\title{
Voice, Cough, and Diurnal Breathing Problems and Quality of Life in Obstructive Sleep Apnea
}

\author{
Ray M. Merrill, PhD, MPH ${ }^{1 *}$; Nelson Roy, PhD²; Jenny Pierce, PhD³; Krishna M. Sundar, MD \\ ${ }^{1}$ Department of Public Health, Brigham Young University, Provo, Utah, USA \\ 2Department of Communication Sciences and Disorders, University of Utah, Salt Lake City, Utah, USA \\ ${ }^{3}$ Division of Otolaryngology, University of Utah, Salt Lake City, Utah, USA \\ ${ }^{4}$ Division of Pulmonary, Critical Care and Sleep Medicine, University of Utah, Salt Lake City, Utah, USA
}

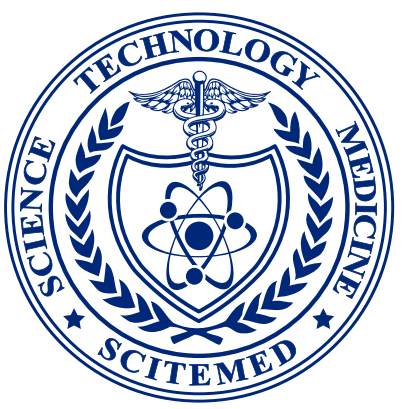

\begin{abstract}
Objective: To assess the burden of possible upper airway related symptoms such as voice, cough, and diurnal dyspnea on SF-36 quality of life (QOL) measures among patients with obstructive sleep apnea (OSA).

Methods: Ninety-four individuals with OSA (53 men, 41 women; mean age 54.8 112.8 ) underwent an extensive telephone interview to collect information regarding the presence and degree of voice, cough, and diurnal breathing symptoms and QOL.

Results: Voice disorder, cough, and diurnal dyspnea were found in $39.4 \%, 27.7 \%$, and $30.9 \%$ of patients, respectively. The percent of patients with 0,1 , 2 , or 3 of these problems was $50.0 \%, 19.2 \%, 13.8 \%$, and $17.0 \%$, respectively. Among OSA patients with voice, cough, and/or diurnal breathing problems, additional decreases in QOL existed. Voice and diurnal breathing problems had the strongest direct negative association with the SF-36 component physical QOL domain, and a voice problem had the strongest direct negative association with the SF-36 component mental QOL domain. There was a linear association between the number of voice, cough, and diurnal breathing problems and reduced SF-36 QOL scores (slope $=-6.5, \mathrm{P}<0.001$ for component physical and $-4.7, \mathrm{P}<0.001$ for component mental), after controlling for age, sex, body mass index, apnea hypopnea index, consistency of continuous positive airway pressure therapy use, and selected chronic health conditions. These symptoms explained $28.5 \%$ and $8.5 \%$ of the variation in the component physical and mental scores, respectively.

Conclusion: Voice, cough, and diurnal dyspnea (perhaps reflecting upper airway dysfunction) are common in OSA and negatively compromise QOL even after controlling for other high impact factors and/or medical comorbidities.
\end{abstract}

\section{INTRODUCTION}

The negative impact of obstructive sleep apnea (OSA) on quality of life (QOL) is well established and occurs across the OSA severity spectrum [1]. The QOL effects are age dependent, most pronounced in midlife, and wane after age 70 years [2]. With more severe OSA, the extent of sexual dysfunction, incontinence, and poorer QOL increases (especially among women) [3,4]. However, recent research has also established that OSA often presents with evidence of potential upper airway related problems involving longstanding voice problems, chronic refractory cough, and diurnal dyspnea, particularly among women [5-11]. Although the origin of such problems in OSA is likely multifactorial $[8,11,12-23]$, it has been postulated that this constellation of voice, cough, and diurnal dyspnea might reflect upper airway inflammation (a common feature of OSA) and/or possible laryngeal hypersensitivity and related laryngeal motor dysfunction $[5,11,22,23]$.

While OSA related burden on QOL is recognized, an expanding literature has also confirmed poorer general QOL (e.g., limited social activities, poorer job performance, more depression, and lower self-esteem) for individuals with voice disorders [24-32], even when adjusting for the effects of several high-impact comorbidities [32]. Indeed, the presence of a voice disorder in OSA negatively associated with both physical and mental health QOL indicators and appeared to be independent of body mass index (BMI) and apnea hypopnea index (AHI) [6]. Likewise, chronic cough has been associated with adverse psychosocial effects on QOL [33], and women compared to men with chronic cough seek more medical attention because their health related QOL is more adversely impacted [34]. Furthermore, diurnal dyspnea associated with chronic diseases such as lung cancer and chronic obstructive pulmonary disease (COPD) also negatively associates with QOL $[35,36]$.

In the current study, we extend our research to assess how chronic cough and diurnal dyspnea affect mental and physical QOL in OSA, as well as how the combination of voice, cough, and diurnal dyspnea impacts QOL. We specifically aim to (1) understand the degree and nature of the reduction in mental and physical QOL related to these specific problems in OSA, (2) determine whether voice, cough, and diurnal dyspnea problems (and related symptoms) contribute disproportionately to QOL deficits, and (3) establish the relative impact of these disorders on QOL in OSA after adjusting for selected variables (age, sex, BMI, AHI, chronic comorbid health conditions, and continuous positive airway pressure [CPAP] therapy), which have been previously associated with QOL in OSA [1-4,37-39]. In this way, we can first determine the extent to which voice, cough, and diurnal dyspnea uniquely and in combination contribute to lower QOL in OSA; and by extension, determine whether allocating additional resources to understand their nature and treatment is justified.

\section{MATERIALS AND METHODS}

Obstructive sleep apnea patients were identified from a chart review of diagnosis codes among individuals seen at the University of Utah Health Care over a three-year period. Medical records of eligible participants were reviewed to verify diagnosis. The diagnosis of OSA was made using attended polysomnography at the University of Utah Sleep-Wake Center-an American Academy of Sleep Medicine accredited sleep laboratory. Each participant had an AHI score which was used to classify OSA as mild (5-14), moderate (15-29), or severe $(\geq 30)[40]$. Confirmed OSA patients who were 18 years or older, able to communicate in English, and had no known cognitive deficits were invited to participate in the current study. Individuals were excluded from participation if they were inpatients, or did not have telephone access for the interview. The medical record review resulted in 246 eligible participants, of which 75 could 
not be reached by phone and 77 declined participation. The final study group consisted of 94 OSA patients (i.e., 38\% of eligible participants).

Following informed consent, an extensive telephone interview was completed using a structured questionnaire. The average interview time was 75 minutes. Interviews were carried out during a four-month period from 2014 to 2015. Trained students from the Department of Communication Sciences and Disorders at the University of Utah conducted the interviews. The questionnaire sought information from five domains: knowledge of OSA severity, duration, and type and compliance of treatment including CPAP devices; current coughing, voice, and diurnal dyspnea disorders with their related history, signs and symptoms; medical and behavioral history (e.g., BMI, AHI, medical comorbidities, snoring and daytime somnolence); social and lifestyle conditions; and psychosocial and occupational history. CPAP use was self-reported, in response to questions surrounding the nature and consistency of use of treatments, if any. The study was approved by the Institutional Review Board at the University of Utah (IRB\#00072401).

Severity of voice disorders, cough, and diurnal dyspnea problems were measured using selected patient reported outcomes measures (PROMs) or indices. The Voice-Related Quality of Life (V-RQOL) is a validated 10-item instrument designed to determine the impact of voice impairment on QOL [26]. Participants were asked to respond to questions about possible voice related problems that occurred within the past two weeks. Scores range from 0 (worst) to 100 (best). V-RQOL cutoff (<94.8) was also used to establish the presence of a voice disorder [41]. The Cough Severity Index (CSI), a 10-item questionnaire, was used to quantify symptoms of upper airway related cough. The CSI has been shown to be statistically reliable, valid, and a clinically sensitive PROM [42]. Scores range from 0 (best) to 40 (worst), and a score greater than 10 was employed to indicate the presence of a significant coughing problem. Using this threshold to establish a cough showed the highest correlation with patients' self-report of whether they currently experience a persistent cough (data not shown). The Dyspnea Index (DI) is also a 10-item validated PROM that aims to quantify symptoms of upper airway related dyspnea. Scores range from 0 (best) to 40 (worst), with a DI score above 10 considered to be within the abnormal range [43].

The Medical Outcomes Study Short Form 36 (SF-36) survey is a psychometrically validated questionnaire developed to assess two overall summary components of QOL (Physical Health and Mental Health), and four subscales for each of these indicators [44]. Physical Health subscales consist of physical function, role-physical, bodily pain, and general health. Mental Health subscales consist of vitality, social functioning, role-emotional, and mental health Each of the QOL measures was converted to a 0 to 100 scale, with 100 representing highest QOL for that domain measure. For instance, a score of 100 on the physical functioning score is obtained by performing all types of physical activity including the most vigorous without limitations due to health; for the role-physical score by having no problems with work or other daily activities; for the bodily pain scale by having no pain or limitations due to pain; the general health scale by evaluating personal health as excellent; the energy/fatigue scale by feeling full of "pep" and energy all the time; the social functioning scale by performing normal social activities without interference from physical or emotional problems; the role-emotional scale by having no problems with work or other daily activities as a result of emotional problems; and the mental health scale by feeling peaceful, happy, and calm all of the time.

Patients with OSA were statistically described using counts, percentages, means, and standard deviations. Mean QOL measures were obtained and compared according to the presence of a current voice problem, cough, and diurnal dyspnea adjusted for selected age, sex, race/ethnicity, education, annual household income, body mass index $\left(\mathrm{kg} / \mathrm{m}^{2}\right)$, $\mathrm{AHI}$, chronic comorbid health conditions (i.e., esophageal reflux, allergies, pneumonia, emphysema, COPD, bronchitis, and asthma), and CPAP use. Compliance with CPAP use and these other measures, with the exception of AHI, was based on patient self-report. The health conditions were measured by asking if they "ever had ..." Multiple regression analyses were used to evaluate the association between current voice problems, cough, and diurnal dyspnea and the SF-36 QOL measures.
The combined influence of 0 through 3 of these problems on the QOL measures was also evaluated. Statistical significance was based on the two-sided test of hypothesis at the 0.05 level of significance. An exploratory assessment using stepwise regression used the 0.10 level of significance. Statistical analyses were performed using SAS 9.4 (SAS Institute, Cary, NC, USA, 2012).

\section{RESULTS}

Distributions for selected variables appear in Table 1. The sample consisted of more males than females, with mean age of 54.7 years (standard deviation 12.8 ) and ages ranging from 23.4 to 80.1 years. Majority of patients were 50 years or older, white, non-Hispanic, had an associate's degree or higher, were obese or morbidly obese, had a household gross income of at least $\$ 60,000$, and had moderate or severe OSA. Approximately $78.7 \%$ of OSA patients were treated using a CPAP device, of whom $71.6 \%$ used it nightly.

Having a current voice problem was significantly more common in women and in those with less education, lower annual household gross income, and in those who did not use CPAP nightly. Having a cough was significantly more common in women and in those with less severe OSA and who did not use CPAP nightly. Experiencing diurnal dyspnea based on the Dyspnea Index was significantly greater in women and among those with lower education and who did not use CPAP nightly. Selected chronic health conditions contribute to voice, cough, and breathing problems.

The combination of voice, cough, and diurnal dyspnea problems (0-3) was assessed, with 47 (50\%) having no problem, 18 (19\%) having one problem, 13 (14\%) having two problems, and 16 (17\%) having three problems. Of those 18 with one problem, voice, cough, and diurnal dyspnea were present in 11, 4 , and 3 individuals, respectively. Of those 13 individuals with two problems, voice and cough were in 3 , voice and diurnal dyspnea in 7 , and cough and diurnal dyspnea in 3.

Unadjusted mean scores for the Short Form 36 (SF-36) QOL measures are shown in Table 2. For the component physical scale, mean scores were significantly worse/lower for those with a current voice, cough, and/or diurnal dyspnea problem. Each of the subscales making up this component measure contributed to this result. For the component mental scale, mean scores were significantly worse/lower for those with a current voice, cough, and/or diurnal dyspnea problem. Vitality, social functioning, and mental health, but not role emotional, contributed to this result.

As the combined number of voice, cough, and diurnal dyspnea problems increased, mean SF-36 QOL scores significantly decreased, with the exception of role-emotional. For example, participants with all three problems compared with no problems had significantly lower mean scores (i.e., 31.8 points lower) for component physical and (20.4 points lower) for component mental. Although voice, cough, and diurnal dyspnea problems were significantly associated with both lower physical and mental SF-36 measures, the impact was slightly greater for the physical measures.

Using stepwise regression, the SF-36 eight-subscale domains were each regressed on voice, cough, and diurnal dyspnea QOL measures, as well as age, sex, BMI, AHI, treatment with CPAP (yes vs. no), and prevalence of selected comorbid health conditions (esophageal reflux, allergies, pneumonia, emphysema, COPD, bronchitis, and asthma) (Table 3). There was a significant negative association between voice and most of the SF-36 QOL measures. Diurnal dyspnea was only significantly negatively associated with bodily pain. Having a current voice problem, higher BMI, and a history of pneumonia, emphysema, COPD, and bronchitis significantly lowered the component physical score, whereas CPAP use significantly increased (improved) this score. Having a current voice problem and a history of allergies significantly lowered the component mental score, and older age and CPAP use significantly increased this score.

Slope estimates from the stepwise models reported in Table 3 were reassessed for just those individuals who were treated with CPAP. In this analysis, rather than adjust for CPAP therapy (yes vs. no), we adjusted for compliance 


\section{ORIGINAL}

Table 1. Voice, Cough, and Diurnal Dyspnea Problems by Selected Variables

\begin{tabular}{|c|c|c|c|c|c|}
\hline Variable & No. & $\%$ & Voice, \% & Cough, $\%$ & Diurnal dyspnea, \% \\
\hline Overall & & & 39.4 & 27.7 & 30.9 \\
\hline \multicolumn{6}{|l|}{ Sex } \\
\hline Men & 53 & 56.4 & 24.5 & 17.0 & 17.0 \\
\hline Women & 41 & 43.6 & 58.5 & 41.5 & 48.8 \\
\hline Chi-square $P$ & & & 0.001 & 0.008 & 0.001 \\
\hline \multicolumn{6}{|l|}{ Age } \\
\hline $20-39$ & 13 & 13.8 & 30.8 & 38.5 & 23.1 \\
\hline $40-49$ & 22 & 23.4 & 27.3 & 27.3 & 27.3 \\
\hline $50-59$ & 24 & 25.5 & 45.8 & 33.3 & 45.8 \\
\hline$\geq 60$ & 35 & 37.2 & 45.7 & 20.0 & 25.7 \\
\hline MH Chi-square P & & & 0.162 & 0.246 & 0.834 \\
\hline \multicolumn{6}{|l|}{ Race/Ethnicity } \\
\hline White, not Hispanic & 79 & 84.0 & 36.7 & 25.3 & 29.1 \\
\hline Hispanic & 10 & 10.6 & 50.0 & 30.0 & 30.0 \\
\hline Other & 5 & 5.3 & 60.0 & 60.0 & 60.0 \\
\hline Chi-square P & & & 0.450 & 0.128 & 0.349 \\
\hline \multicolumn{6}{|l|}{ Schooling } \\
\hline$<\mathrm{HS}$ & 3 & 3.2 & 66.7 & 00.0 & 66.7 \\
\hline HS/GED & 32 & 34.0 & 46.9 & 31.2 & 37.5 \\
\hline Associate's degree & 18 & 19.2 & 44.4 & 33.3 & 33.3 \\
\hline Bachelor's degree & 18 & 19.2 & 38.9 & 27.8 & 38.9 \\
\hline Master's degree & 13 & 13.8 & 23.1 & 38.5 & 15.4 \\
\hline Doctoral degree & 10 & 10.6 & 20.0 & 00.0 & 0 \\
\hline MH Chi-square P & & & 0.036 & 0.424 & 0.012 \\
\hline \multicolumn{6}{|c|}{ Annual household gross income } \\
\hline$<\$ 20,000$ & 16 & 19.3 & 68.8 & 43.8 & 50.0 \\
\hline$\$ 20,000-\$ 39,999$ & 15 & 18.1 & 66.7 & 33.3 & 33.3 \\
\hline$\$ 40,000$ - \$59,999 & 8 & 9.6 & 37.5 & 37.5 & 37.5 \\
\hline$\geq \$ 60,000$ & 44 & 53.0 & 27.3 & 20.4 & 25.0 \\
\hline Missing & 11 & & & & \\
\hline MH Chi-square P & & & 0.001 & 0.071 & 0.084 \\
\hline \multicolumn{6}{|l|}{ Body mass index } \\
\hline Normal & 5 & 5.3 & 20.0 & 47.1 & 0.0 \\
\hline Overweight & 23 & 24.5 & 34.8 & 24.5 & 34.8 \\
\hline Obese & 49 & 52.1 & 44.9 & 21.7 & 30.6 \\
\hline Morbidly obese & 17 & 18.1 & 35.3 & 20.0 & 35.3 \\
\hline MH Chi-square P & & & 0.536 & 0.111 & 0.403 \\
\hline
\end{tabular}




\begin{tabular}{|c|c|c|c|c|c|}
\hline Variable & No. & $\%$ & Voice, \% & Cough, \% & Diurnal dyspnea, \% \\
\hline \multicolumn{6}{|l|}{ Apnea-hypopnea index } \\
\hline Mild & 45 & 47.9 & 46.7 & 40.0 & 35.6 \\
\hline Moderate & 19 & 20.2 & 47.4 & 21.0 & 42.1 \\
\hline Severe & 30 & 31.9 & 23.3 & 13.3 & 16.7 \\
\hline MH Chi-square P & & & 0.053 & 0.010 & 0.107 \\
\hline \multicolumn{6}{|l|}{ Using CPAP } \\
\hline Yes & 74 & 78.7 & 37.8 & 25.7 & 27.0 \\
\hline No & 20 & 21.2 & 45.0 & 35.0 & 45.0 \\
\hline Chi-square $P$ & & & 0.563 & 0.408 & 0.123 \\
\hline \multicolumn{6}{|l|}{ Consistency of CPAP } \\
\hline Nightly & 53 & 71.6 & 28.3 & 13.2 & 18.9 \\
\hline Less than nightly & 21 & 28.4 & 61.9 & 57.1 & 47.6 \\
\hline Chi-square P & & & 0.007 & $<0.001$ & 0.012 \\
\hline \multicolumn{6}{|l|}{ Ever had ... } \\
\hline Esophageal reflux & 61 & 64.9 & $2.3(1.1-4.7)$ & $1.9(1.2-3.1)$ & $4.7(1.5-14.3)$ \\
\hline Respiratory allergies & 40 & 42.6 & $1.2(0.7-1.9)$ & $1.2(0.9-1.8)$ & $1.9(1.0-3.5)$ \\
\hline Pneumonia & 41 & 43.6 & $0.8(0.5-1.3)$ & $1.3(0.9-1.8)$ & $1.4(0.8-2.5)$ \\
\hline Emphysema & 4 & 4.3 & $1.3(0.5-3.5)$ & $1.3(0.7-2.4)$ & $2.6(1.4-5.0)$ \\
\hline COPD & 9 & 9.6 & $1.5(0.8-2.8)$ & $1.6(1.2-2.2)$ & $2.5(1.4-4.4)$ \\
\hline Bronchitis & 48 & 51.1 & $0.9(0.6-1.5)$ & $1.8(1.2-2.6)$ & $1.6(0.8-3.0)$ \\
\hline Asthma & 29 & 30.8 & $1.2(0.7-2.0)$ & $1.5(1.102 .1)$ & $2.4(1.3-4.3)$ \\
\hline
\end{tabular}

COPD, chronic obstructive pulmonary disease; CPAP, continuous positive airway pressure; GED, general educational development; HS, high school; MH, Mantel Haenszel. Column 3 percentages sum to 100 . Columns 4-6 percentages indicate the amount of the respective problems that correspond with the levels of the selected variables in the table. A current (within past two weeks) voice problem is based on the Voice-Related Quality of Life (V-RQOL): $\max =100$ (best), $\min =0$ (worst), $<94.8=$ voice problem (37 Yes and $57 \mathrm{No}$ ). A coughing problem is based on the Cough Severity Index (CSI): $\mathrm{max}=40$ (worst), $\min$ $=0$ (best), $>10=$ coughing problem ( 26 Yes and $68 \mathrm{No})$. A diurnal dyspnea problem is based on Dyspnea Index (DI): Max $=40$ (worst), min = 0 (best), $>10=a b n o r m a l$ (breathlessness) $(29$ Yes and $65 \mathrm{No})$. Risk
factors at the end of the table reflect prevalence ratios $(95 \%$ confidence intervals), and have been previously reported [11].

to CPAP therapy (nightly vs. otherwise), along with age, sex, BMI, AHI, and the comorbid health conditions. Similar variables tended to significantly contribute to the models, as those shown in Table 3. Having a voice problem was significantly associated with lower physical function, role physical, general health component physical, vitality, social functioning, mental health, and component mental; having diurnal dyspnea significantly associated with lower bodily pain; and having a cough did not significantly associate with any of the QOL measures, in the adjusted models.

Slope estimates of the association between each of the SF-36 eight-subscale domains and component measures and number of voice, cough, and diurnal dyspnea problems are shown in Table 4. As the total number of problems increase, each of the subscale and component scores significantly decrease, with role-emotional insignificant, in the adjusted model. Specifically, as the number of problems increase by one, the component physical scale decreases by 6.7 points and component mental decreases by 5.0 , on average. Voice, cough, and diurnal dyspnea problems explain $21.5 \%$ of the variation in the component physical score and $10.5 \%$ of the variation in the component mental score, after adjusting for age, sex, BMI, AHI, CPAP use, esophageal reflux, allergies, pneumonia, emphysema, COPD, bronchitis, and asthma. To assess the influence of consistency of CPAP therapy (nightly vs. otherwise), the models in Table 4 were estimated again, but for the CPAP users only. Estimates were adjusted for age, sex, BMI, AHI, the above-referenced comorbidities and consistency of CPAP use (nightly vs. otherwise). Estimates in this sub-analysis that now adjusted for consistency of CPAP use were similar or larger to the original analysis, with voice, cough, and diurnal dyspnea problems now explaining $28.5 \%$ of the variation in the component physical score and $8.5 \%$ of the variation in the component mental score (Table 4).

To better understand the specific symptoms that might be potentiating $\mathrm{QOL}$ reductions (i.e., at a granular level), analyses were undertaken at the in- dividual item level for each of the PROMS. In this regard, physical and mental component scores were inversely associated with the severity of several items comprising the measures of V-RQOL, CSI, and DI (data not shown). Stepwise regression was then used to identify the $\mathrm{V}-\mathrm{RQOL}, \mathrm{CSI}$, and DI items that most strongly associated with the component physical and mental QOL measures. Each V-RQOL item was measured from 1 (none) to 5 (as bad as it gets). (Note that these results are rescaled to get the 0 (worst) to 100 (best) component V-RQOL score.) Each CSI item was measured from 0 (never) to 4 (always). Each DI item was measured from 0 (never) to 4 (always). Analyses were also adjusted for age, sex, BMI, AHI, and CPAP use (yes vs. no).

For both the component physical and mental scores, only one V-RQOL item remained significant: "Do you run out of air and need to take frequent breaths when talking?" The adjusted regression estimate was -9.1 $(P<0.001)$ in the component physical model and $-5.9(P=0.003)$ in the component mental model. Thus, for each unit increase in response to this item, physical component QOL decreased by 9.1 and mental component QOL decreased by 5.9, on average, suggesting that this item contributed disproportionately to reduced QOL. For both the component physical and mental models, only one CSI item remained significant: "My coughing problem affects my voice." Estimates for the two models were $-3.9(P=0.021)$ and $-3.5(P=0.025)$, respectively. Finally, for the component physical model, two DI items were significant "My breathing problem causes me to restrict my personal and social life" and "My breathing problem makes me feel stressed." Corresponding estimates were -8.2 $(P=0.004)$ and $-4.5(P=0.018)$. For the component mental model, only "My breathing problem causes me to restrict my personal and social life" remained significant, with an estimate of $-9.4(P<0.001)$.

Thus, of the items that comprise V-RQOL, running out of air and needing to take frequent breaths to talk had the greatest negative impact on physical and mental QOL measures. Likewise, the CSI item most strongly negatively 


\begin{tabular}{|c|c|c|c|c|c|c|c|c|c|c|}
\hline Variable & $\begin{array}{l}\text { Physical } \\
\text { function }\end{array}$ & & $\begin{array}{l}\text { Role } \\
\text { physical }\end{array}$ & & $\begin{array}{l}\text { Bodily } \\
\text { pain }\end{array}$ & & $\begin{array}{l}\text { General } \\
\text { health }\end{array}$ & & $\begin{array}{l}\text { Component } \\
\text { physical }\end{array}$ & \\
\hline & $M=70.4$ & $S D=28.8$ & $M=63.0$ & $S D=42.7$ & $M=64.1$ & $S D=18.0$ & $M=52.9$ & $S D=23.2$ & $M=61.3$ & $S D=23.8$ \\
\hline & Estimate & $\operatorname{Pr}>|t|$ & Estimate & $\operatorname{Pr}>|t|$ & Estimate & $\operatorname{Pr}>|t|$ & Estimate & $\operatorname{Pr}>|t|$ & Estimate & $\operatorname{Pr}>|t|$ \\
\hline Voice & -14.0 & 0.004 & -30.4 & $<0.001$ & -19.6 & $<0.001$ & -14.0 & 0.004 & -19.8 & $<0.001$ \\
\hline Cough & -11.5 & 0.031 & -16.7 & 0.090 & -14.3 & 0.025 & -11.5 & 0.031 & -16.8 & 0.002 \\
\hline $\begin{array}{l}\text { Diurnal } \\
\text { dyspnea }\end{array}$ & -11.5 & 0.026 & -25.1 & 0.008 & -22.7 & $<0.001$ & -11.5 & 0.026 & -21.3 & $<0.001$ \\
\hline \multicolumn{11}{|c|}{ Problem reference $=0$} \\
\hline 1 & -3.2 & 0.650 & -11.4 & 0.314 & 4.8 & 0.503 & -11.0 & 0.080 & -5.6 & 0.343 \\
\hline 2 & -10.2 & 0.204 & -12.4 & 0.334 & -21.2 & 0.010 & -13.0 & 0.068 & -11.8 & 0.080 \\
\hline 3 & -39.0 & $<0.001$ & -41.1 & 0.001 & -27.4 & $<0.001$ & -18.0 & 0.007 & -31.8 & $<0.001$ \\
\hline \multirow[t]{3}{*}{ Variable } & Vitality & & $\begin{array}{l}\text { Social } \\
\text { functioning }\end{array}$ & & $\begin{array}{l}\text { Role } \\
\text { emotional }\end{array}$ & & $\begin{array}{l}\text { Mental } \\
\text { health }\end{array}$ & & $\begin{array}{l}\text { Component } \\
\text { mental }\end{array}$ & \\
\hline & $M=46.5$ & $S D=23.5$ & $M=77.0$ & $S D=28.7$ & $M=72.0$ & $S D=39.8$ & $M=70.9$ & $S D=20.8$ & $M=65.0$ & $S D=21.5$ \\
\hline & Estimate & $\operatorname{Pr}>|t|$ & Estimate & $\operatorname{Pr}>|t|$ & Estimate & $\operatorname{Pr}>|t|$ & Estimate & $\operatorname{Pr}>|t|$ & Estimate & $\operatorname{Pr}>|\mathrm{t}|$ \\
\hline Voice & -12.7 & 0.010 & -21.7 & $<0.001$ & -8.8 & 0.299 & -12.5 & 0.004 & -13.1 & 0.003 \\
\hline Cough & -10.3 & 0.057 & -16.0 & 0.014 & -16.2 & 0.077 & -11.8 & 0.013 & -12.9 & 0.008 \\
\hline $\begin{array}{l}\text { Diurnal } \\
\text { dyspnea }\end{array}$ & -7.4 & 0.161 & -16.6 & 0.009 & -9.4 & 0.295 & -11.1 & 0.016 & -10.4 & 0.028 \\
\hline \multicolumn{11}{|c|}{ Problem reference $=0$} \\
\hline 1 & -11.7 & 0.068 & -14.9 & 0.048 & -1.8 & 0.869 & -3.7 & 0.502 & -7.2 & 0.209 \\
\hline 2 & -3.4 & 0.637 & -10.5 & 0.216 & 1.0 & 0.934 & -11.6 & 0.068 & -6.4 & 0.324 \\
\hline 3 & -17.9 & 0.008 & -30.2 & $<0.001$ & -21.7 & 0.061 & -17.7 & 0.003 & -20.4 & 0.001 \\
\hline
\end{tabular}

M, mean; OSA, obstructive sleep apnea; Pr, probability; SD, standard deviation; SF-36, study short form 36. Slope estimates were derived using regression analysis and represent how the presence of the respective problem or combination of problems (1, 2, or 3 vs. 0 ) influence the mean SF-36 scores. For example, the mean physical function score is 14.0 lower for those with a current voice problem compared with OSA patients without a current voice problem.

associated with the SF-36 component physical and mental QOL measures involved their cough affecting their voice. Although cough has a direct effect on $\mathrm{QOL}$, in the fully adjusted model that includes voice, it became insignificant. Thus, cough negatively associates with QOL, in part because of its negative impact on the voice. Finally, among the items comprising the DI, physical and mental component QOL measures were most strongly negatively associated with breathing restricting personal and social life. However, in the fully adjusted model, which included voice, cough, diurnal dyspnea (and other variables), only having a voice problem and higher BMI were associated with worse social functioning (Table 3). Hence, breathing and cough problems appear to negatively correlate with social functioning through their association with voice.

\section{DISCUSSION}

The negative impact of OSA on QOL is well established [1-4], and, as expected, mean QOL measures for the SF-36 eight-subscale domains for our OSA patients were lower than normative values in the United States [41]. However, the current study confirmed that the presence of possible upper airway related disorders such as voice, cough, and diurnal dyspnea added significantly to the overall QOL burden, beyond what would be expected by OSA alone. In general, SF-36 QOL physical and mental health component and subscale scores tended to become consistently worse as the combined number of voice, cough, and diurnal dyspnea problems increased. As the number of problems increased from 0 to 3 , the physical and mental scale and subscale scores worsened, after adjusting for age, sex, BMI, AHI, consistency of CPAP therapy, and chronic comorbid health conditions (esophageal reflux, allergies, pneumonia, emphysema, COPD, bronchitis, and asthma). Thus, even after controlling for other high impact factors and/or comorbidities that reportedly influence QOL in OSA [1-4], the presence of these possible upper airway problems significantly lowered physical and mental QOL, uniquely explaining $28.5 \%$ and $8.5 \%$ of the variation in the component physical and mental scores, respectively.

In fully adjusted regression models, which included the three potential upper airway related problems, as well as age, sex, BMI AHI, consistency of CPAP therapy, esophageal reflux, allergies, pneumonia, emphysema, COPD, bronchitis, and asthma, voice problems played a central role in negatively impacting the mean QOL component physical and mental score. Diurnal dyspnea only negatively impacted bodily pain and cough was not significantly associated with any of the QOL measures. Thus, as compared with cough and diurnal dyspnea, voice had a larger direct negative impact on QOL. Yet, having two or all three of these problems had a markedly greater negative effect on the QOL measures than just having a voice problem alone. In addition, inspection of individual items that contributed disproportionately to reduced social functioning revealed that breathing and cough problems appear to negatively associate with QOL through their effects on voice.

In OSA, reductions in QOL are often driven by several neurocognitive consequences (i.e., daytime sleepiness, memory loss, loss of mental alertness, reduced care in avoiding danger, impaired cognitive control of behavior, and greater risk of accidents) [45]. Nocturnal CPAP therapy reduces daytime sleepiness [46], which, in turn, may lower the risk of other neurocognitive problems. Likewise, consistent (nightly) CPAP treatment has been shown to reduce the frequency of voice, cough, and diurnal breathing problems which might be upper airway related $[6,11,47,48]$. In the current study, CPAP use was associated with significantly better component physical and mental QOL, yet the untoward effects of voice and diurnal breathing problems on QOL persisted even after adjustment for nightly CPAP use.

Limitations exist in this study. First, the results are based on data from a single institution retrospective evaluation of a relatively small sample size. Second, data are primarily from self-report and using such report to disam- 


\begin{tabular}{|c|c|c|c|c|c|c|c|c|c|c|}
\hline Variable & $\begin{array}{l}\text { Physical } \\
\text { function }\end{array}$ & & $\begin{array}{l}\text { Role } \\
\text { physical }\end{array}$ & & $\begin{array}{l}\text { Bodily } \\
\text { pain }\end{array}$ & & $\begin{array}{l}\text { General } \\
\text { health }\end{array}$ & & $\begin{array}{l}\text { Component } \\
\text { physical }\end{array}$ & \\
\hline & Estimate & $\operatorname{Pr}>|t|$ & Estimate & $\operatorname{Pr}>|t|$ & Estimate & $\operatorname{Pr}>|t|$ & Estimate & $\operatorname{Pr}>|t|$ & Estimate & $\operatorname{Pr}>|t|$ \\
\hline Voice & -15.5 & $<0.001$ & -33.0 & $<0.001$ & & & -11.9 & 0.008 & -17.3 & $<0.001$ \\
\hline \multicolumn{11}{|l|}{ Cough } \\
\hline Diurnal dyspnea & & & & & -18.8 & 0.003 & & & & \\
\hline \multicolumn{11}{|l|}{ Age } \\
\hline Sex & & & & & 10.5 & 0.068 & & & & \\
\hline BMI & -1.2 & $<0.001$ & & & & & -0.5 & 0.012 & -0.8 & $<0.001$ \\
\hline \multicolumn{11}{|l|}{ AHI } \\
\hline CPAP & 17.5 & $<0.001$ & & & & & & & 11.2 & 0.008 \\
\hline \multicolumn{11}{|l|}{ Esophageal reflux } \\
\hline Pneumonia & -10.0 & 0.010 & -16.3 & 0.043 & & & & & -8.9 & 0.015 \\
\hline \multicolumn{11}{|l|}{ Emphysema } \\
\hline COPD & -41.4 & $<0.001$ & & & & & -17.89 & 0.018 & -22.8 & $<0.001$ \\
\hline Bronchitis & -9.4 & 0.015 & -25.4 & 0.002 & & & -8.7 & 0.049 & -11.2 & 0.002 \\
\hline \multirow[t]{2}{*}{ Variable } & Vitality & & $\begin{array}{l}\text { Social } \\
\text { functioning }\end{array}$ & & $\begin{array}{l}\text { Role } \\
\text { emotional }\end{array}$ & & $\begin{array}{l}\text { Mental } \\
\text { health }\end{array}$ & & $\begin{array}{l}\text { Component } \\
\text { mental }\end{array}$ & \\
\hline & Estimate & $\operatorname{Pr}>|t|$ & Estimate & $\operatorname{Pr}>|t|$ & Estimate & $\operatorname{Pr}>|t|$ & Estimate & $\operatorname{Pr}>|t|$ & Estimate & $\operatorname{Pr}>|t|$ \\
\hline Voice & -11.5 & 0.012 & -22.1 & $<0.001$ & & & -12.7 & 0.004 & -14.2 & $<0.001$ \\
\hline \multicolumn{11}{|l|}{ Cough } \\
\hline \multicolumn{11}{|l|}{ Diurnal dyspnea } \\
\hline Age & & & 0.4 & 0.083 & 0.9 & 0.004 & 0.4 & 0.006 & 0.5 & 0.004 \\
\hline \multicolumn{11}{|l|}{ Sex } \\
\hline BMI & -0.4 & 0.064 & -0.6 & 0.032 & & & & & & \\
\hline \multicolumn{11}{|l|}{$\mathrm{AHI}$} \\
\hline CPAP & 15.0 & 0.006 & & & & & & & 10.2 & 0.038 \\
\hline Esophageal reflux & & & & & & & -7.2 & 0.096 & & \\
\hline Allergies & & & & & -23.9 & 0.002 & & & -9.5 & 0.019 \\
\hline Bronchitis & -11.4 & 0.011 & & & & & & & & \\
\hline
\end{tabular}

AHI, apnea-hypopnea index; BMI, body mass index; COPD, chronic obstructive pulmonary disease; CPAP, continuous positive airway pressure; Pr, probability; SF-36, study short form 36. Estimates were derived using stepwiseregression analysis. Variables were eligible to enter or exit the model if significant at the 0.1 level. The slope estimates indicate the extent to which voice, cough, diurnal dyspnea, age, sex, BMI, AHI, CPAP use, and chronic comorbid health conditions (i.e., esophageal reflux, allergies, pneumonia, emphysema, COPD, bronchitis, and asthma) are associated with change in the specific physical and mental SF-36 subscale and component measures. For example, a voice problem is associated with a mean decrease in the component physical measure of 17.3 and in the component mental measure of 14.2.

biguate upper from lower airway cough or breathing disorders is problematic. The study did not include objectively measured CPAP compliance based on device downloads or ascertain the type of mask used with CPAP. Therefore, the impact of CPAP therapy on these complaints of voice, cough, and diurnal dyspnea could not be fully assessed. Third, because only 94 of the 246 eligible participants could be reached and agreed to participate, generalization of the results should be done with caution. Fourth, only OSA patients were considered. Although estimated associations between the upper airway symptoms (voice, cough, and diurnal dyspnea) and QOL accounted for potential confounding effects of selected chronic comorbid health conditions, including non-OSA patients may have better account for unmeasured confounders and allowed us to compare the measured associations according to OSA status. These limitations may represent a direction in future studies.

\section{CONCLUSION}

This study confirmed that voice and other problems potentially reflecting upper airway dysfunction matter in OSA and deserve clinical and research attention. Half of the OSA patients had one or more of voice, cough, and diurnal dyspnea and each of the problems negatively impacted QOL. The adverse effects of such problems persisted, even after controlling for high impact factors/comorbidities as previously shown to affect quality of life such as age, sex, AHI, BMl, chronic health conditions, and consistency of CPAP use. Given the high frequency of these problems (and their significant effects on $\mathrm{QOL}$ ) in OSA, further research is warranted to (1) understand the nature of these disorders (when present) in OSA and (2) develop effective treatments to lessen their adverse impact on QOL.

\section{ARTICLE INFORMATION}

*Correspondence: Ray M. Merrill, PhD, MPH, Department of Public Health, 2063 Life Science Building, College of Life Sciences, Brigham Young University, Provo, UT 84602, USA. Email: Ray_Merrill@byu.edu

Received: May 05, 2020; Accepted:Jun. 18, 2020; Published: Jul. 02, 2020

DOI: $10.24983 /$ scitemed.aohns.2020.00132

Disclosure: All authors gave critical revision of the manuscript for important intellectual content and approved the final version of the manuscript. 


\begin{tabular}{|c|c|c|c|c|c|c|c|c|c|c|c|c|c|c|}
\hline \multicolumn{3}{|l|}{$\begin{array}{l}\text { Physical } \\
\text { function }\end{array}$} & \multicolumn{3}{|l|}{$\begin{array}{l}\text { Role } \\
\text { physical }\end{array}$} & \multicolumn{3}{|l|}{$\begin{array}{l}\text { Bodily } \\
\text { pain }\end{array}$} & \multicolumn{3}{|l|}{$\begin{array}{l}\text { General } \\
\text { health }\end{array}$} & \multicolumn{3}{|c|}{$\begin{array}{l}\text { Component } \\
\text { physical }\end{array}$} \\
\hline Estimate & $\operatorname{Pr}>|t|$ & $\begin{array}{l}\text { Partial } \\
\text { R-Square }\end{array}$ & Estimate & $\operatorname{Pr}>|t|$ & $\begin{array}{l}\text { Partial } \\
\text { R-Square }\end{array}$ & Estimate & $\operatorname{Pr}>|t|$ & $\begin{array}{l}\text { Partial } \\
\text { R-Square }\end{array}$ & Estimate & $\operatorname{Pr}>|t|$ & $\begin{array}{l}\text { Partial } \\
\text { R-Square }\end{array}$ & Estimate & $\operatorname{Pr}>|t|$ & $\begin{array}{l}\text { Partial } \\
\text { R-Square }\end{array}$ \\
\hline-5.7 & 0.002 & 0.205 & -11.6 & 0.001 & 0.107 & -7.7 & 0.002 & 0.150 & -4.6 & 0.026 & 0.093 & -6.7 & $<0.001$ & 0.215 \\
\hline-6.2 & 0.007 & 0.289 & -15.4 & $<0.001$ & 0.157 & -9.9 & 0.001 & 0.181 & -2.1 & 0.5262 & 0.008 & -6.5 & 0.010 & 0.285 \\
\hline \multicolumn{3}{|l|}{ Vitality } & \multicolumn{3}{|l|}{$\begin{array}{l}\text { Social } \\
\text { functioning }\end{array}$} & \multicolumn{3}{|l|}{$\begin{array}{l}\text { Role } \\
\text { emotional }\end{array}$} & \multicolumn{3}{|l|}{$\begin{array}{l}\text { Mental } \\
\text { health }\end{array}$} & \multicolumn{3}{|c|}{$\begin{array}{l}\text { Component } \\
\text { mental }\end{array}$} \\
\hline Estimate & $\operatorname{Pr}>|t|$ & $\begin{array}{l}\text { Partial } \\
\text { R-Square }\end{array}$ & Estimate & $\operatorname{Pr}>|t|$ & $\begin{array}{l}\text { Partial } \\
\text { R-Square }\end{array}$ & Estimate & $\operatorname{Pr}>|t|$ & $\begin{array}{l}\text { Partial } \\
\text { R-Square }\end{array}$ & Estimate & $\operatorname{Pr}>|t|$ & $\begin{array}{l}\text { Partial } \\
\text { R-Square }\end{array}$ & Estimate & $\operatorname{Pr}>|t|$ & $\begin{array}{l}\text { Partial } \\
\text { R-Square }\end{array}$ \\
\hline-3.2 & 0.106 & 0.024 & -8.0 & 0.001 & 0.133 & -2.8 & 0.118 & 0.003 & -5.1 & 0.021 & 0.106 & -5.0 & 0.006 & 0.105 \\
\hline-5.1 & 0.040 & 0.103 & -6.5 & 0.030 & 0.055 & -4.5 & 0.220 & 0.011 & -4.4 & 0.067 & 0.152 & -4.7 & 0.024 & 0.085 \\
\hline
\end{tabular}

Pr, probability; SF-36, study short form 36. Estimates adjusted for age, sex, body mass index (BMI), apnea-hypopnea index (AHI), continuous positive airway pressure (CPAP) use, esophageal reflux, allergies, pneumonia, emphysema, chronic obstructive pulmonary disease (COPD), bronchitis, and asthma. Estimates were derived using regression analysis and represent how the number of problems influence mean SF-36 scores. For example, for in the mal $\mathrm{m}$-36 scere explained by the $(\mathrm{N}=74)$, and are adjusted for age, sex, BMI, AHI, and consistency of CPAP use (nightly vs. other).

Ethics Approval and Consent to Participate: The study is in accordance with the ethical standards of the 1964 Helsinki declaration and its later amendments or comparable ethical standards.

Funding: The study did not receive any specific grant from funding agencies in the public, commercial, or not-for-profit sectors.

Conflict of Interest: The authors report no financial or other conflict of interest relevant to this article, which is the intellectual property of the authors.

Acknowledgments: The authors wish to gratefully acknowledge the important contributions of the following undergraduate students in the Department of Communication Sciences and Disorders at the University of Utah: Rexton Cook, Brandy Hamblen, Heather Reseska, and Natalie Van Vranken.

Copyright @ 2020 The Authors. This is an open-access article distributed under the terms of the Creative Commons Attribution 4.0 International License (CC-BY).

\section{REFERENCES}

1. Lee SA, Paek JH, Han SH. Sleep hygiene and its association with daytime sleepiness, depressive symptoms, and quality of life in patients with mild obstructive sleep apnea. $J$ Neurol Sci 2015;359(1-2):445-449.

2. Addison-Brown $\mathrm{KJ}$, Letter AJ, Yaggi K, et al. Age differences in the association of obstructive sleep apnea risk with cognition and quality of life.J Sleep Res 2014;23(1):69-76.

3. Irer B, Celikhisar A, Celikhisar H, Bozkurt O, Demir O. Evaluation of Sexual Dysfunction, Lower Urinary Tract Symptoms and Quality of Life in Men With Obstructive Sleep Apnea Syndrome and the Efficacy of Continuous Positive Airway Pressure Therapy. Urology 2018;121:86-92.

4. Silva GE, Goodwin JL, Vana KD, Quan SF. Obstructive Sleep Apnea and Quality of Life: Comparison of the SAQLI, FOSQ, and SF-36 Questionnaires. Southwest J Pulm Crit Care 2016;13(3):137-149.

5. Nguyen AT, Jobin V, Payne R, Beauregard J, Naor N, Kimoff RJ. Laryngeal and velopharyngeal sensory impairment in obstructive sleep apnea. Sleep 2005;28(5):585-593.

6. Roy N, Merrill RM, Pierce J, Sundar KM. Voice Disorders in Obstructive Sleep Apnea: Prevalence, Risk Factors, and the Role of CPAP. Ann Otol Rhinol Laryngol 2019;128(3):249-262.

7. Gouveia CJ, Yalamanchili A, Ghadersohi S, et al. Are chronic cough and laryngopharyngeal reflux more common in obstructive sleep apnea patients? Laryngoscope 2019;129(5):1244-1249.

8. Wang TY, Lo YL, Liu WT, et al. Chronic cough and obstructive sleep apnoea in a sleep laboratory-based pulmonary practice. Cough 2013;9(1):24.

9. Chan KK, Ing AJ, Laks L, Cossa G, Rogers P, Birring SS. Chronic cough in patients with sleep-disordered breathing. Eur Respir J 2010;35(2):368-372.

10. Aihara $\mathrm{K}, \mathrm{Oga} \mathrm{T}$, Yoshimura C, et al. Measurement of dyspnea in patients with obstructive sleep apnea. Sleep Breath 2013;17(2):753-761.

11. Roy N, Merrill RM, Pierce J, Sundar KM. Evidence of Possible Irritable Larynx Syndrome in Obstructive Sleep Apnea: An Epidemiologic Approach.J Voice 2020 [Online ahead of print].
12. Chan K, Ing A, Birring SS. Cough in obstructive sleep apnoea. Pulm Pharmacol Ther 2015;35:129-131.

13. Sundar KM, Daly SE. Chronic cough and OSA: an underappreciated relationship. Lung 2014;192(1):21-25.

14. Sundar KM, Daly SE. Chronic cough and OSA: a new association? J Clin Sleep Med 2011;7(6):669-677.

15. Boyd JH, Petrof BJ, Hamid Q, Fraser R, Kimoff RJ. Upper airway muscle inflammation and denervation changes in obstructive sleep apnea. Am J Respir Crit Care Med 2004;170(5):541-546.

16. Lee CH, Hong SL, Rhee CS, Kim SW, Kim JW. Analysis of upper airway obstruction by sleep videofluoroscopy in obstructive sleep apnea: a large population-based study. Laryngoscope 2012;122(1):237-241.

17. Carpagnano GE, Spanevello A, Sabato R, Depalo A, Turchiarelli V, Foschino Barbaro MP. Exhaled $\mathrm{pH}$, exhaled nitric oxide, and induced sputum cellularity in obese patients with obstructive sleep apnea syndrome. Trans/ Res 2008;151(1):45-50.

18. Sariman N, Levent E, Cubuk R, Yurtlu S, Benli Aksungar F. Bronchial hyperreactivity and airway wall thickening in obstructive sleep apnea patients. Sleep Breath 2011;15(3):341350.

19. Cohen S, Doyle WJ, Alper CM, Janicki-Deverts D, Turner RB. Sleep habits and susceptibility to the common cold. Arch Intern Med 2009;169(1):62-67.

20. Talwar A, Sahni S, Kim EJ, Verma S, Kohn N. Dyspnea, depression and health related quality of life in pulmonary arterial hypertension patients. J Exerc Rehabil 2015;11(5):259-265.

21. Guyatt GH, Townsend M, Berman LB, Pugsley SO. Quality of life in patients with chronic airflow limitation. BrJ Dis Chest 1987;81(1):45-54.

22. Teramoto $\mathrm{S}$, Sudo $\mathrm{E}$, Matsuse $\mathrm{T}$, et al. Impaired swallowing reflex in patients with obstructive sleep apnea syndrome. Chest 1999;116(1):17-21.

23. Valbuza JS, de Oliveira MM, Zancanella E, et al. Swallowing dysfunction related to obstructive sleep apnea: a nasal fibroscopy pilot study. Sleep Breath 2011;15(2):209-213.

24. Smith $\mathrm{E}$, Verdolini K, Gray S, et al. Effect of voice disorders on quality of life.J Med SpeechLang Path 1996;4(4):223-244.

25. Cohen SM, Dupont WD, Courey MS. Quality-of-life impact of non-neoplastic voice disorders: a meta-analysis. Ann Otol Rhinol Laryngol 2006;115(2):128-134.

26. Hogikyan ND, Sethuraman G. Validation of an instrument to measure voice-related quality of life (V-RQOL). J Voice 1999;13(4):557-569.

27. Karlsen T, Sandvik L, Heimdal JH, Hjermstad MJ, Aarstad AK, Aarstad HJ. Health-related Quality of Life as Studied by EORTC QLQ and Voice Handicap Index Among Various Patients With Laryngeal Disease.J Voice 2017;31(2):251 e217-251 e226.

28. Merrill RM, Anderson AE, Sloan A. Quality of life indicators according to voice disorders and voice-related conditions. Laryngoscope 2011;121(9):2004-2010.

29. Merrill RM, Roy N, Lowe J. Voice-related symptoms and their effects on quality of life. Ann Otol Rhinol Laryngol 2013;122(6):404-411.

30. Roy N, Tanner K, Merrill RM, Wright C, Miller KL, Kendall KA. Descriptive Epidemiology of Voice Disorders in Rheumatoid Arthritis: Prevalence, Risk Factors, and Quality of Life Burden.J Voice 2016;30(1):74-87.

31. Tanner K, Pierce JL, Merrill RM, Miller KL, Kendall KA, Roy N. The Quality of Life Burden Associated With Voice Disorders in Sjogren's Syndrome. Ann Otol Rhinol Laryngol 2015;124(9):721-727. 


\section{ORIGINAL}

32. DeVore EK, Carroll TL, Rosner B, Shin ע. Can voice disorders matter as much as life-threatening comorbidities to patients' general health? Laryngoscope 2019 [Online ahead of print].

33. French CL, Irwin RS, Curley FJ, Krikorian CJ. Impact of chronic cough on quality of life. Arch Intern Med 1998;158(15):1657-1661.

34. French $\mathrm{CT}$, Fletcher $\mathrm{KE}$, Irwin RS. Gender differences in health-related quality of life in patients complaining of chronic cough. Chest 2004;125(2):482-488.

35. Smith EL, Hann DM, Ahles TA, et al. Dyspnea, anxiety, body consciousness, and quality of life in patients with lung cancer.J Pain Symptom Manage 2001;21(4):323-329.

36. Okutan O, Tas D, Demirer E, Kartaloglu Z. Evaluation of quality of life with the chronic obstructive pulmonary disease assessment test in chronic obstructive pulmonary disease and the effect of dyspnea on disease-specific quality of life in these patients. Yonsei Med J 2013;54(5):1214-1219.

37. Wang R, Wu C, Zhao Y, et al. Health related quality of life measured by SF-36: a population-based study in Shanghai, China. BMC Public Health 2008;8:292.

38. Korhonen PE, Seppala T, Jarvenpaa S, Kautiainen H. Body mass index and health-related quality of life in apparently healthy individuals. Qual Life Res 2014;23(1):67-74.

39. Kuhn E, Schwarz El, Bratton DJ, Rossi VA, Kohler M. Effects of CPAP and Mandibular Advancement Devices on Health-Related Quality of Life in OSA: A Systematic Review and Meta-analysis. Chest 2017;151(4):786-794.

40. Hudgel DW. Sleep Apnea Severity Classification - Revisited. Sleep 2016;39(5):1165-1166.

41. Kupfer RA, Hogikyan EM, Hogikyan ND. Establishment of a normative database for the
Voice-Related Quality of Life (V-RQOL) measure.J Voice 2014;28(4):449-451.

42. Shembel AC, Rosen CA, Zullo TG, Gartner-Schmidt JL. Development and validation of the cough severity index: a severity index for chronic cough related to the upper airway. Laryngoscope 2013;123(8):1931-1936.

43. Gartner-Schmidt JL, Shembel AC, Zullo TG, Rosen CA. Development and validation of the Dyspnea Index (DI): a severity index for upper airway-related dyspnea. J Voice 2014;28(6):775-782.

44. Ware JE, Jr., Sherbourne CD. The MOS 36-item short-form health survey (SF-36). I. Conceptual framework and item selection. Med Care 1992;30(6):473-483.

45. Vijayan VK. Morbidities associated with obstructive sleep apnea. Expert Rev Respir Med 2012;6(5):557-566.

46. Marshall NS, Barnes M, Travier N, et al. Continuous positive airway pressure reduces daytime sleepiness in mild to moderate obstructive sleep apnoea: a meta-analysis. Thorax 2006;61(5):430-434.

47. Karakurt SE, Karakus MF, Eravci FC, Kum N, Ozcan M, Ozcan KM. Evaluation of the Relationship Between the Required Pressure Level in Continuous Positive Airway Pressure Treatment and Voice in Patients With Obstructive Sleep Apnea Syndrome.J Voice 2019 [Online ahead of print]

48. Sundar KM, Willis AM, Smith S, Hu N, Kitt JP, Birring SS. A Randomized, Controlled, Pilot Study of CPAP for Patients with Chronic Cough and Obstructive Sleep Apnea. Lung 2020;198(3):449-457. 